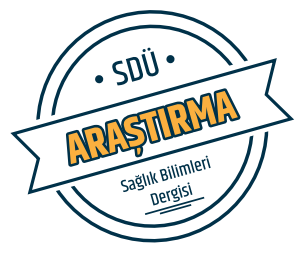

Sdü Sağlık Bilimleri Enstitüsü Dergisi / Cilt 9 Sayı 2 / 2018

\title{
Beden Dışı Şok Dalga ile Taş Kırma Tedavisinin Başarı ve Sonucu Üzerine Etkili Faktörler
}

\section{Factors Affecting Success and Outcome of Extracorporeal Shock Wave Lithotripsy Treatment}

\author{
Osman Ergün ${ }^{1}$ \\ 'Süleyman Demirel Üniversitesi, Tıp Fakültesi, Üroloji Anabilim Dalı, Isparta, Türkiye.
}

\section{Özet}

Amaç: Beden dışı şok dalga ile taş kırma tedavisinin sonucu ve başarısı üzerine etkili olabilecek faktörleri analiz etmek.

Materyal-Metot: Üroloji Kliniği taş kırma ünitesine başvuran ve çalışmaya dahil edilme kriterlerine uyan 220 hastanın verileri retrospektif olarak analiz edildi. Beden dışı şok dalga ile taş kırma tedavisi için kontraendikasyonu olmayan ve kontrastsız alt-üst abdominal bilgisayarlı tomografide en uzun boyutu $0,5-2,5 \mathrm{~cm}$ olan, tek orta pol böbrek taşına sahip hastalar çalışmaya dahil edildi. Vücut kitle indeksinin, taş boyutunun, taş dansitesinin, cilt-taş mesafesinin, yaşın ve cinsiyetin beden dışı şok dalga ile taş kırma tedavisinin başarı ve sonucu üzerine etkileri değerlendirildi.

Bulgular: Hastaların yaş ortalaması $43,4 \pm 12,6$ idi ve vücut kitle indeksi ortalamalar1 $27,7 \pm 4,9 \mathrm{~kg} / \mathrm{m} 2$ idi. Ortalama taş

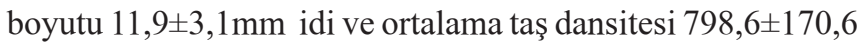
HÜ idi. $30(\% 13,6)$ hastada beden dışı şok dalga ile taş kırma tedavisi işleminde başarısızlık tespit edildi. Başarısızlık gelișen 21 hastaya perkütan nefrolitotomi, 9 hastaya retrograt ürterorenoskopi uyguland.

Sonuç: Beden dışı şok dalga ile taş kırma tedavisinin başarısızlığı ile kadın cinsiyete sahip olma, vücut kitle indeksi, obezite, cilt-taş mesafesi, taş boyutu ve taş dansitesinin $>1000$ HÜ olması arasında ilişki vardır.

Anahtar kelimeler: Beden Dışı Şok Dalga ile Taş Kırma Tedavisi, Taş Dansitesi, Taş Boyutu, Vücut Kitle İndeksi.

\begin{abstract}
Objective: To analyze the factors that may be influential on the outcome and success of extracorporeal shock wave lithotripsy treatment.
\end{abstract}

Material-Method: The data of 220 patients who refered to extracorporeal shock wave lithotripsy treatment units' of our urology clinic and met the inclusion criteria were retrospectively analyzed. Patients with a single mid-pole renal stone with a longest dimension of $0.5-2.5 \mathrm{~cm}$ on the noncontrast abdominal computed tomography and without contraindication to extracorporeal shock wave lithotripsy treatment were included the study. The efficacy of extracorporeal shock wave lithotripsy treatment success and outcome were evaluated with body mass index, stone size, stone density, skin to stone distance, age and gender .

Results: The mean age and body mass index of the patients were $43.4 \pm 12.6$ and $27.7 \pm 4.9 \mathrm{~kg} / \mathrm{m} 2$. The mean stone size and the stone density of the petients were $11.9 \pm 3.1$ $\mathrm{mm}$ and $798.6 \pm 170.6 \mathrm{HU}$. The $30(13.6 \%)$ patients, in whom extracorporeal shock wave lithotripsy treatment failed, underwent ureteroscopy (n:9) or percutaneous nephrolithotomy (n:21).

Conclusions: There is a relationship between the failure of extracorporeal shock wave lithotripsy treatment and the presence of female sex, body mass index, obesity, skin to stone distance, stone size, and stone density $>1000 \mathrm{HU}$.

Keywords: Extracorporeal Shock Wave Lithotripsy Treatment, Body Mass Index, Stone Density, Stone Size.

\section{Giriş}

Ülkemiz taş kuşağında olan ülkeler arasında yer almaktadır. Türkiye taş prevelansı $\% 14,8$ olarak bildirilmiştir (1). Beden dışı şok dalga ile taş kırmanın (ESWL) keşfi, üriner sistem taş hastalığı tedavisinde yeni bir çığır açmıştır. ESWL tedavisi, üriner sistem taş tedavisinde çok yaygın olarak kullanılan ve oldukça önemli bir yere sahip olan bir tedavi yöntemidir. ESWL, bir kaynakta üretilen enerjinin taşın üzerine odaklanması, üriner sistemdeki taşın vücut dışından gönderilen şok dalgaları ile kırılarak kendiliğinden düşebilecek parçalara ayrılması esasına dayanır. ESWL' nin en büyük avantajı yüksek etkinliğe sahip olması ve non-invasiv olmasidır. Anestezi gerektirmemesi, ayaktan uygulanabilir oluşu, hastaların hızlı bir şekilde günlük yaşantılarına dönebiliyor olmaları ve cerrahi ile kıyaslanınca düşük komplikasyon ve morbidite oranlarına sahip olması nedeni ile çoğu üriner sistem taşlarında ESWL ilk tedavi seçeneği haline gelmiştir.
DOI: $10.22312 /$ sdusbed.432014

Müracaat tarihi: 08.06.2017

Kabul tarihi: 13.06 .2018

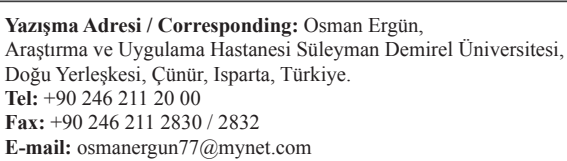


ESWL tedavisinin tüm bu yüz güldürücü sonuçlarına rağmen, taşın yapısına, yerleşimine, boyutuna, eşlik eden komorbiditelere ve hastaya bağlı değişkenlere bağlı olarak tedavi başarısızlıkla sonuçlanabilmektedir. Bu hastalarda ek tedavi yöntemleri (perkütan nefrolitotomi, üreterorenoskopi, açık taş cerrahisi vb) gerekebilmektedir. Buda zaman kaybına ve maliyet artışına neden olabilmektedir.

Biz bu çalışmada kliniğimize üriner sitem taş şikayeti ile başvuran ve ESWL tedavisi uygulanan hastaların verilerini retrospektif olarak değerlendirerek, ESWL tedavisinin sonucu ve başarısı üzerine etkili olabilecek faktörleri analiz etmeyi amaçladık.

\section{Materyal-Method}

Üroloji kliniği taş kırma ünitesine başvuran ve çalışmaya dahil edilme kriterlerine uyan 220 hastanın verileri analiz edildi. ESWL için kontraendikasyonu olmayan ve kontrastsız alt-üst abdominal bilgisayarlı tomografide (NCCT) en uzun boyutu 0,5-2,5 cm olan, tek orta pol böbrek taşına sahip hastalar çalışmaya dahil edildi. Vücut kitle indeksi (VKI) hastaların kilosu, boyunun karesine bölünerek tespit edildi. Hastaların işlem öncesi çekilen NCCT filminde taşın boyutu, yerleşim yeri, taşın ortalama dansitesi, taş cilt mesafesi, böbrek parankim kalınlığı ve toplayıcı sistemde dilatasyon durumu değerlendirilerek, kayıt altına alındı. Taş dansitesi housfield ünitesi (HÜ) kullanılarak hesaplandı. ESWL ortalama 15005000 (ortalama: 3600) şok dalgası uygulanarak ve 14-22 (ortalama: 18) kV güç kullanılarak, Elmed COMPLIT® lithotripsy (ELMED Elektronik ve Medikal sanayi, Türkiye) cihazı kullanılarak uygulandı. İki seans arası süre ise ortalama 10 gün idi. Üç seans sonunda kırılmayan veya yeterli derecede kırılıp dökülmeyen taşlarda ESWL işlemi başarısız olarak kabul edildi. Hastalar her ESWL seansı sonrası ve son ESWL seans1 sonras1 3. haftada kontrole çağrıldı. ESWL tedavisinin tamamlanmasindan 3 hafta sonra direkt üriner sistem grafisi ve NCCT çekilerek taştan temizlenme oranları belirlendi. Taşın parçalanıp dökülmesi ( $<4$ mm taşlar dikkate alınmadı), böbrek taşına bağlı yakınmaların kaybolması ve böbrek taşı için başka bir tedavi yöntemine gerek duyulmaması "başarılı sonuç" olarak kabul edildi.

Veriler ortalama artı/eksi standart sapma ve maksimum minimum değerleri olarak sunuldu. Verilerin normal dağılıma uyup uymadığını belirlemek için tek-örneklem KolmogorovSmirnov testi uygulandı. Gruplar arası farklılığı belirlemek için Chi-kare testi, Kruskal-Wallis testi ve Mann-Whitney U testi; parametreler arasındaki bağıntıları araştırmak için Pearson veya Spearman korelasyon analizi uygulandi. İstatistiksel analiz için SPSS 15.0 istatistik programı kullanıldı. P değeri 0.05 'in altı istatistiksel olarak anlamlı kabul edildi.

\section{Bulgular}

Verilerine eksiksiz ulaşılarak çalışmaya dahil edilme kurallarına uyan hasta sayısı 220 idi. Çalışmaya dahil edilen hastaların 141'i erkek, 79'u kadın idi. Hastaların yaş ortalaması $43,4 \pm 12,6$ idi ve VKİ ortalamalan $27,7 \pm 4,9 \mathrm{~kg} / \mathrm{m} 2$ idi. Ortalama taş boyutu $11,9 \pm 3,1 \mathrm{~mm}$ idi ve ortalama taş dansitesi 798,6 $\pm 170,6$ HÜ idi. $30(\% 13,6)$ hastada ESWL işleminde başarısızlık tespit edildi. Başarısızlık gelişen 21 hastaya PNL, 9 hastaya retrograt ürterorenoskopi uygulandi. Başarısızlık tespit edilen hastalar yaş, cinsiyet, VKİ, obezite (VKI $\geq 30$ ), taş boyutu, cilt ile taş arasındaki mesafe, taş dansitesi ve taş dansitesinin $>1000$ Hü olup olmaması yönünden değerlendirildi (Tablo1-2). ESWL başarısızlığ1 ile kadın cinsiyete sahip olma, VKİ, obezite, cilt-taş mesafesi, taş boyutu ve taş dansitesinin $>1000$ HÜ olması arasında istatistiki olarak anlamlı fark tespit edildi. ESWL başarısızlığı ile VKİ arasında güçlü $(r=0,67$ ve $p=0,028)$ korelasyon tespit edildi. Yine ESWL başarısızlı̆̆ı ile taş dansitesinin $>1000$ HÜ olması arasında güçlü $(r=0,73$ ve $\mathrm{p}=0,002$ ) korelasyon tespit edildi. ESWL başarısızlı̆̆ kadın cinsiyet, VKİ ve taş boyutu arasında düşük ( $\mathrm{r}=0-0,25$ ve $\mathrm{p}<0,05)$ korelasyon tespit edildi. ESWL başarısızlığ 1 ile taş boyutu ve cilt-taş mesafesi arasında orta $(r=0,26-0,50$ ve $\mathrm{p}<0,05)$ korelasyon tespit edildi. ESWL prosedürü uygulanan $10(\% 4,5)$ hastada prosedür sonrası taş yolu gelişti. Taş yolu gelişen hastalardan 7'si taşlarını spontan olarak dökerken 2 hastaya URS prosedürü uygulandi. Son seansdan 1 ay sonra yapılan kontrollerde ESWL başarısı \%86,4 (190/220) olarak tespit edildi. ESWL prosedürü başarılı kabul edilen hastaların 164 'ü tamamen taşdan temizlenmiş iken 26 hasta da 4 mm'den küçük taş vardı.

Tablo 1. ESWL başarısız olguların cinsiyet, obezite ve taş dansitesi yönünden karşılaştırılması.

\begin{tabular}{lccc}
\hline Değişkenler & $\mathbf{n}$ & $\begin{array}{c}\text { ESWL başarısız } \\
\text { olgular (\%) }\end{array}$ & $\mathrm{p}$ \\
\hline $\begin{array}{c}\text { Cinsiyet } \\
\text { Kadın }\end{array}$ & 79 & $18(22,8)$ & 0,024 \\
$\quad$ Erkek & 141 & $12(8,5)$ & \\
\hline $\begin{array}{c}\text { Obezite } \\
\text { Obez değil }\end{array}$ & 129 & $11(8,5)$ & 0,018 \\
$\begin{array}{l}\text { Obez } \\
\text { (VKİ } \geq 30)\end{array}$ & 91 & $21(23,1)$ & \\
\hline $\begin{array}{c}\text { Taş dansitesi } \\
\leq 1000 \text { HÜ }\end{array}$ & 197 & $17(8,6)$ & 0,034 \\
$>1000$ HÜ & 23 & $6(26,1)$ & \\
\hline VKI: Vücut kitle indeksi, HÜ: Housfield ünitesi
\end{tabular}

\section{Tartışma}

Böbrek taşlarının cerrahi tedavisinde ilk amaç minimal morbidite ile maksimum taşsızlık oranını sağlamaktır. ESWL ve endoürolojik teknolojilerdeki ilerleme ile neredeyse bütün böbrek taşları minimal invaziv tekniklerle tedavi edilebilmektedir. Özellikle yetişkin hastalarda 20 mm'nin altındaki böbrek ve üreter taşlarında ilk tedavi seçeneği ESWL olarak kabul edil-miştir (2). Uygun tedavi belirlenmeden önce taşa bağlı faktörler, böbrek anatomisi, hastaya bağlı klinik faktörler, uygulanması planlanan tedavilerin morbiditeleri ve elde bulunan teknik cihazlar bir kompleks olarak değerlendirilmelidir. 
Böbrek taşlarının cinsiyete göre görülme oranı, az sayıdaki bazı çalışmalar dışında genel olarak erkeklerde kadınlardan daha yüksek oranda görüldüğü yönündedir (35). Çalışmamızda cinsiyetin ESWL başarısı üzerine etkisi varmı diye değerlendirdik. Kadın cinsiyetin ESWL başarısı üzerinde negatif etkisi olduğunu orataya koyduk.

Tablo 2. ESWL başarısı üzerine etkili olabilcek faktörlerin karşılaştırmalı analizi.

\begin{tabular}{|c|c|c|c|}
\hline \multirow{2}{*}{ Değișkenler } & \multicolumn{2}{|c|}{ ESWL } & \multirow{2}{*}{ p } \\
\hline & Başarılı & Başarısız & \\
\hline Yaş & $43,1 \pm 13,5$ & $42,14 \pm 13,7$ & 0,13 \\
\hline VKİ & $25,6 \pm 4,2$ & $31,6 \pm 4,6$ & 0,012 \\
\hline $\begin{array}{l}\text { Taş dansitesi } \\
\text { (HÜ) }\end{array}$ & $743,1 \pm 178,3$ & $783,75 \pm 207,4$ & 0,238 \\
\hline $\begin{array}{l}\text { Taş boyutu } \\
\text { (mm) }\end{array}$ & $11,3 \pm 3,7$ & $14,7 \pm 4,9$ & 0,041 \\
\hline $\begin{array}{l}\text { Cilt-taş } \\
\text { mesafesi }(\mathrm{cm})\end{array}$ & $8,7 \pm 3,4$ & $12,2 \pm 2,1$ & 0,024 \\
\hline
\end{tabular}

VKİ: Vücut kitle indeksi, HÜ: Housfield ünitesi, mm: milimetre, cm: santimetre

Taşın böbrekteki lokalizasyonu ile ESWL başarısı arasındaki ilişikiyi araştıran bir çok çalışma yapılmıştır $(5,6)$. Özellikle alt kaliks taşlarında ESWL başarısı daha düşük tespit edilmiştir (7-9). Literatür değerlendirildiğinde ESWL sonrası oluşan kırıntıların alt kalikslerden temizlenememesinin sebebi net açıklanamamıştır. İlk başlarda yer çekiminin etkisi olabileceği düşünülürken sonrasında değişik anotomik durumların bu durumun nedeni olabileceği ortaya konmuştur. Alt kaliksleri toplayan tek infidubulumu olan hastalar bir kaç infindubulumu olanlara göre kırılan taşı düşürme eğilimleri daha yüksektir. Alt kaliks infundibulumu ile renal pelvis arasındaki açıda taş düşürme açısından önemlidir. 90 dereceden daha yüksek açıya sahip hastalar taşları daha kolay düşürmektedirler. Biz çalışmamızda sadece orta pol taşlarını değerlendirmeye alarak bu karışık anatomik yapıdan kaynaklı olarak ESWL başarısının değerlendirilmesinde karmaşıklığa neden olabilecek durumların önüne geçmeyi amaçladık. Böylece ESWL başarısı üzerine primer olarak etki eden faktörleri daha net ortaya koymayı amaçladık. Çalışmamızda tek orta pol böbrek taşlarında ESWL tedavisinin başarısını \% 86,4 olarak tespit ettik.

Taş yükü, hem boyut hemde sayı olarak seçilecek tedavide sağlanacak taşsızlık oranını etkileyen bir faktördür (1012). ESWL sonrası başarı oranının taş boyutundan olumsuz etkilenmesi sadece böbrek taşları için değil aynı zamanda üreter taşları içinde geçerlidir. Taş yükünü yalnız en büyük taşın büyüklüğü değil böbrekte bulunan bütün taşlar oluşturmaktadır. Bundan dolayı taş yükünden kaynaklı veri analizinde oluşabilecek karışıklıkları en aza indirmek ve daha net değerlendirme sağlayabilmek için çalışmamızda sadece böbrekte aynı lokalizasyondaki tek böbrek taşları değerlendirmeye alındı. Yaptığımız analizler sonucunda ESWL başarısı ile taş boyutu arasında istatistiki olarak anlamlı ilişki tespit ettik.
Düşürülmüş veya daha önce çıkarılmış taşların kompozisyonu çok önelidir. Çünkü bu taşlar ca-oksalat monohidrat veya bruşit içeriyorsa kırma işlemlerine karşı fiziksel direnç oranı diğer taş tiplerine göre daha yüksek olabilir. Genelde taşlar tek bir kompozisyondan değil komplex bir oluşumdan meydana gelmektedir (13). Taşlar görüntüleme yöntemlerindeki taş yoğunluğuna göre değerlendirildiğinde, genelde kompleks yapılı taşlar oldukları için, birbirleri ile değerler bakımından çakışmakta ve yoğunluğa göre taş tipini tahmin etmek zorlaşmaktadır $(14,15)$. Biz çalışmamızda, ESWL başarısını hem taş yoğunluğu hemde yoğunluğunun 1000 HÜ üzerinde olup olmamasına göre değerlendirdik. Taş dansitesi ile ESWL başarısı arasında bir ilişki ortaya koyamadık. Ancak taş dansitesini 1000 HÜ değerine göre sınıfladığımızda, 1000 HÜ üzerindeki değerlerde ESWL başarısının istatistiki olarak anlamlı şekilde düştüğünü tespit ettik. Dolayısı ile belki taş dansitesinden taşın cinsini tahmin edemeyebiliriz, ancak taşın ESWL tedavisine vereceği cevabı önceden öngörebiliriz. Özellik 1000 HÜ dansite üzerindeki taşlarda, taş boyutu büyük ise, hastanın taşa bağlı semptomları aktif halde ise ve tedavi gecikmesi hastada ek patolojilere yol açabilme durumu varsa; bu grup hastalarda hasta ile konuşularak ESWL tedavisi yerine PNL, urs gibi daha invaziv ancak başarı şansı daha yüksek tedaviler denenebilir.

VKI'nin bir çok hastalığın gelişiminde ve tedavisinin başarısında etkili olduğu tıp alanında yapılan bir çok çalışmada ortaya konmuştur. Pareek ve ark. (16) VKİ ile ESWL başarısı arasında ilişki olduğunu bildirmişlerdir. Buna ek olarak El-Nahas ve ark. (17) yaptıkları çalışmada, VKİ ile ESWL başarısı arasındaki ilişikiyi ortaya koydukları gibi cilt taş mesafesi ile başarı arasında da ilişki olduğunu da ortaya koymuşlardır. Bizde çalışmamızda VKİ ve cilt taş mesafesi ile ESWL başarısı arasında anlamlı ilişiki tespit ettik.

\section{Sonuc}

Sonuç olarak, üriner sistem taşlarının tedavisinde ESWL, etkinliğinin yanında invaziv olmaması, hastanede yatış olmaması ve düşük morbidite oranları ve daha az böbrek yaralanma riski nedeniyle daha fazla tercih edilen bir tedavi alternatifidir. ESWL'de başarı taş boyutundan, VKI'den, taş yoğunluğundan ve cilt taş mesafesinden etkilenmektedir. Başarı oranlarımız literatürle uyumlu bulunmuştur.

\section{Teşekkür}

Konya Eğitim ve Araştırma Hastanesi Taş Kırma ünitesinde görevli teknisyen Sayın Adem Asil'e bu çalışmaya katkılarından dolayı teşekkür ederiz.

\section{Kaynaklar}

1. Tefekli A, Tok A, Altundere F, Barut M, Berberoğlu Y, et al. Üriner sistem taş hastalarında yaşam tarzı ve beslenme alışkanlıkları. Türk Üroloji Dergisi 2005; 31: 113-8.

2. Preminger GM, Tiselius HG, Assimos DG, Alken P, Buck AC, Gallucini M, et al. 2007 Guideline for the management of ureteral calculi. Eur Urol 2007; 52(6): 1610-31.

3. Pearle MS, Calhoun EA, Curhan GC. Urologic diseases 56 
4. Muslumanoglu AY, Binbay M, Yuruk E, Akman T, Tepeler A, Esen T, et al. Updated epidemiologic study of urolithiasis in Turkey. I: Changing char-acteristics of urolithiasis. Urol Res 2011; 39(4): 309-14.

5. Davarcı M, Rifaioğlu M, Yalçınkaya FR, İnci M. Üriner sistem taşlarında iki senelik şok dalgası ile taş kırma tedavisi sonuçları. Dicle Med J 2012; 39 (3): 377-380

6. Güneş M, Pirinççi N, Geçit İ, Kerem T, Bilici S, Göksu M. Üriner sistem taşlarının ESWL ile tedavisinde taşın boyut ve lokalizasyonunun taştan temizlenme oranına etkisi. Van Tıp Dergisi 2011; 18(3): 136-40.

7. May DJ, Chandroke PS. Efficacy and cost effectiveness of ESWL for solitary pole renal calculi. J Urol 1998; 159: 24-7.

8. Sampaio FJ, D'Anunciacao AL, Silva EC. Comparative follow-up of patients with acute and obtuse infundibulumpelvic angle submitted to extracorporeal shockwave lithotripsy for lower caliceal stones: preliminary report and proposed study design. J Endourol 1997; 11: 157-61.

9. Elbahnasy AM, Shalhav AL, Hoenig DM, Elashry OM, Smith DS, McDougall EM, et al. Lower calyceal Stone clearance after shock wave lithotripsy or ureteroscopy: The impact of lower pole radiographic anatomy. J Urol 1998; 159: 676-82.

10. Logarakis NF, Jewett MA, Luymes J, Honey RJ. Variation in clinical outcome following shock wave lithotripsy. J Urol 2000; 163: 721-725.

11. Seo JB, Seo YJ, Lee SD, Chung MK. Therapeutic
Experience of Domestic SDS-3000 Lithotriptor in 440 Patients with Urinary Stone. Korean J Urol. 1999; 40: 138142.

12. Taş S, Tuğcu V, Mutlu B, Kalfazade N, Bitkin A, Taşçı Aİ. Kliniğimizde üroloji asistanlarınca uygulanan ESWL tedavisinin sonuçları. Yeni Üroloji Dergisi 2011; 6 (1): 13-17.

13. Daudan M, Donsimoni R, Hennequin C, Fellahi S, Le Moel G, Paris M, et al. Sex- and age-related composition of 10617 calculi analyzed by infrared spectroscopy. Urol Res 1995; 23: 319-26.

14. Nakada S, Hoff DG, Attai S, Heisey D, Blankenbaker D, Pozniac M. Determination of stone composition by noncontrast spiral computed tomography in the clinical setting. Urology 2000; 55: 816-9.

15. Sheir KZ, Mansour O, Madbouly K, Elsobky E, Abdelkalek M. Determination of the chemical composition of urinary calculi by noncontrast spiral computerized tomography. Urol Res 2005; 33: 99-104.

16. Pareek G, Armenakas NA, Panagopoulos G, Bruno JJ, Fracchina JA. Extracorporeal shock wave lithotripsy success based on body mass index and Hounsfield units. Urology 2005; 65: 33-6.

17. El-Nahas AR, El-Assmy AM, Mansour O, Sheir KZ. A prospective multivariate analysis of factors predicting stone disintegration by extracorporeal shock wave lithotripsy: the value of high-resolution noncontrast computed tomography. Eur Urol. 2007 Jun; 51(6): 1688-93. 